Revista de Estudios Histórico-Jurídicos

[Sección historia del derecho europeo]

XLII (Valparaíso, Chile, 2020)

[pp. 377-394]

\title{
El ARRENDAMIENTO DE OBRA E INDUSTRIA EN EL CÓDIGO CIVIL FRANCÉS
}

[The Hiring of Work and Labour in the French Civil Code]

\author{
Pablo Scotto Benito* \\ Universidad de Barcelona, España
}

\section{RESUMEN}

El Código napoleónico (1804) introduce una modificación importante en el arrendamiento de obra e industria con respecto a la tradición jurídica francesa: el centro del contrato ya no es aquello que se entrega, sino quién paga y quién cobra. Esta forma de ver las cosas -a la que subyace la idea de que la fuerza de trabajo humana es una propiedad como otra cualquiera- supone una cierta equiparación, a la baja, entre arrendamiento de obra y arrendamiento de industria o servicios. El artesano deja de ser un arrendatario, para convertirse en un arrendador de su propio trabajo, igual que el criado. Esto no significa, de todas formas, que ambos sean tratados de la misma manera: el Código dedica grupos distintos de artículos a unos y a otros. Las gens de travail están a disposición de quien los emplea, mientras que los entrepreneurs d'ouvrages gozan de independencia en las tareas a realizar.

\section{Palabras Clave}

Código napoleónico - arrendamiento de obra e industria - trabajo - clases sociales - Robert Joseph Pothier - Jean Domat.

\section{ABSTRACT}

The Napoleonic Code (1804) introduces an important change in the hiring of work and labour with respect to French legal tradition: the centre of the contract is no longer what is handed over, but who pays and who gets paid. This view -whose underlying idea is that human labour is a property like any other-implies a certain downward levelling of 'hiring of work' standards to 'hiring of labour' ones. The craftsman ceases to be a lessee, to become a lessor of his own labour, just like the servant. This does not mean, however, that both are treated in the same way: the Code devotes different groups of articles to each one. The gens de travail are available to those who employ them, while the entrepreneurs d'ouvrages enjoy independence in the tasks they perform.

\section{KEY WORDS}

Napoleonic Code - hiring of work and labour [hiring of labour and industry] work and labour - social classes - Robert Joseph Pothier - Jean Domat.

RECIBIDO el 11 de abril de 2020 y ACEPTADO el 5 de junio de 2020

* Universidad de Barcelona, Facultad de Derecho, Departamento de Ciencia Política, Derecho Constitucional y Filosofía del Derecho. Av. Diagonal 684 (08034) Barcelona. Dirección electrónica: pablo.scotto.benito@ub.edu 


\section{El CONTRATO DE ARRENDAMIENTO}

El Code civil des Français, promulgado el 21 de marzo de 1804, sitúa el contrato de obra e industria dentro de los contratos de arrendamiento, como era habitual en la doctrina de la época. Lo hace introduciendo unas novedades que, por su sutileza, no son fáciles de ver a simple vista. Para entenderlas, conviene empezar explicando la forma en que entiende el contrato de arrendamiento Robert Joseph Pothier, que es el jurista que más influye en el Código en relación con este asunto.

Pothier empieza su Traité du contrat de louage (1764) señalando que existen dos tipos de contrato de arrendamiento: el arrendamiento de cosas y el de obra. Las seis primeras partes del Tratado están dedicadas al arrendamiento de cosas, y solamente la séptima al arrendamiento de obra. El enfoque del autor está en consonancia con la tradición romanista, si bien se puede decir que la distinción que establece entre ambos tipos de arrendamiento es más marcada que en los textos clásicos.

El arrendamiento es, en efecto, un tipo contractual que aparece en las fuentes jurídicas romanas, bajo el nombre de locatio conductio ${ }^{1}$. No existe, sin embargo, una definición clara de este tipo de contrato en dichas fuentes. Se trata más bien de un paraguas con el que se designan diferentes tipos de relaciones jurídicas. Los juristas del siglo XIX consideraron que dentro del arrendamiento había tres tipos contractuales distintos, y trasladaron esta clasificación al derecho romano, distinguiendo entre arrendamiento de cosas (locatio conductio rei), arrendamiento de obras (locatio conductio operis) y arrendamiento de servicios (locatio conductio operarum). Sin embargo, como señala Schulz ${ }^{2}$, la tripartición no está realmente presente en el mundo clásico.

Para los juristas romanos, lo fundamental es que se arriende algo, ya sea una cosa, una obra o los servicios de alguien. En todos los casos, una persona, el locator, pone algo a disposición de otra persona, el conductor, durante cierto período de tiempo. Locare quiere decir colocar, o poner a disposición, y conducere quiere decir llevar junto a uno o conducir: de ahí los nombres de las personas involucradas en el contrato, y el nombre del propio contrato.

Pothier, como ya hemos dicho, distingue más claramente que los romanos entre el arrendamiento de cosas y el arrendamiento de obra. El arrendamiento de cosas, afirma, es un contrato por el cual uno de los dos contratantes se obliga a dar el disfrute o el uso de una cosa al otro, durante un tiempo convenido y a cambio de un cierto precio, que este último se compromete a pagar ${ }^{3}$. El arrendamiento de obra es un contrato por el cual una de las partes contratantes da una cierta obra

${ }^{1}$ Véase Sala Bañuls, Juan; López Clarós, Pedro y Fábregas del Pilar, Francisco, Digesto romano-español (2 a ed., Madrid, Imprenta de la Viuda de Domínguez, 1856), I, libro 19, título 2, pp. 184-189.

${ }^{2}$ Schulz, Fritz, Derecho romano clásico (trad. cast. de José Santa Cruz Teigeiro, Barcelona, Bosch, 1960), p. 518.

${ }^{3}$ POTHIER, Robert Joseph, Traité du contrat de louage, selon les règles tant du for de la conscience, que du for extérieur (París, Debure; Orleans, Rouzeau-Montaut, 1764), p. 3. 
a hacer a la otra, que se compromete a realizarla por un precio convenido entre ellas, que aquella que ha dado la obra a hacer se compromete a pagar ${ }^{4}$.

En el arrendamiento de cosas, el objeto del contrato es el uso de una determinada cosa. En el arrendamiento de obra, el objeto del contrato es la obra dada a hacer. Esto, que puede parecer obvio, implica la siguiente consecuencia, que ya no lo es tanto: en el arrendamiento de cosas y en el arrendamiento de obra, la figura del arrendador y del arrendatario están, por así decirlo, intercambiadas. Siendo más precisos: están intercambiadas en lo que respecta a quien paga el precio acordado.

En el arrendamiento de cosas, es el arrendatario (conducteur, preneur, locataire) quien está obligado a pagar el precio del arrendamiento al arrendador (locateur, bailleur). En el arrendamiento de obra, en cambio, es el arrendador quien se obliga a pagar el precio al arrendatario 5 . Pensemos, para ilustrar el primer caso, en el arrendamiento de una casa: el arrendatario puede usar o disfrutar de la casa, pero a cambio debe comprometerse a pagar al arrendador el precio acordado. Pensemos, en cambio, en el arrendamiento de unas telas para teñirlas: el arrendador, que entrega las telas, tiene a su vez la obligación de pagar. En el arrendamiento de cosas, lo que se paga es el precio del arrendamiento, el precio del uso de la cosa. Siguiendo con el ejemplo, el precio de poder disfrutar de la casa durante un cierto tiempo. En el arrendamiento de obra, por el contrario, el precio no va ligado ya al arrendamiento. Lo que se paga no es el uso de la cosa, sino la obra: es decir, el proceso de transformación de los materiales entregados. Lo que se paga no es el disfrute de las telas, sino la obra que el arrendatario hace sobre ellas mientras dura el arrendamiento. Retener esto tiene mucha importancia para comprender aquello en lo que el Código Civil se distingue de Pothier y, en consecuencia, de la tradición jurídica francesa.

Profundicemos un poco más en el arrendamiento de obra. En este tipo de contrato, dice Pothier, el arrendador (locateur) da o encarga una obra y se compromete a pagar un determinado precio, mientras que el arrendatario (conducteur) se compromete a hacer la obra. El locateur es quien debe proporcionar la mayor parte de materiales al conducteur, pues en caso de que este último no solo aporte la obra, sino también los materiales a transformar, estaríamos ante un contrato de compraventa, y no de arrendamiento. Un ejemplo claro de este tipo de contratos es, como ya hemos dicho, la entrega de unas telas para lavarlas o teñirlas. Pero también el encargo a un sastre para realizar un traje, siempre que el locateur proporcione la tela, que es lo principal del vestido; es un arrendamiento, y no una compraventa, dice Pothier, por mucho que el sastre aporte los botones, el hilo, e incluso el forro o la cinta. Se incluye también en este tipo de contratos el encargo a un arquitecto para construir una casa, porque el locateur aporta lo principal, que es el terreno.

${ }^{4}$ Ibíd., p. 350.

${ }^{5}$ Ibíd., p. 351. 


\section{El ARRENDAMIENTO DE OBRA Y LOS SERVICIOS DE LOS CRIADOS}

Caracterizado de este modo, es fácil advertir que el arrendamiento de obra de Pothier no puede incluir en su seno a los contratos de prestación de servicios. En efecto, estos son tratados dentro del arrendamiento de $\operatorname{cosas}^{6}$. Al hablar de las cosas que no pueden ser vendidas y sí arrendadas, Pothier dice que un hombre libre puede alquilar su propio trabajo: "Un hombre libre no es susceptible de un Contrato de venta, pero puede arrendar sus servicios. Obsérvese, no obstante, que solamente los servicios innobles y mensurables en dinero [appréciables à prix d'argent] son susceptibles de un contrato de arrendamiento, como aquellos de los criados y criadas [serviteurs et servantes], de los trabajadores [manœuvres], de los artesanos, etc." ${ }^{7}$.

Al hablar de servicios "innobles y mensurables en dinero", Pothier pretende distinguir los servicios de los criados y otros trabajadores manuales de los servicios de los profesionales liberales. La contratación de estos últimos no se rige por las normas del contrato de arrendamiento, afirma, sino por las del contrato de mandato. El dinero que un cliente da a un abogado, por ejemplo, no es el precio del servicio que este le proporciona, que no es mensurable, sino una muestra de reconocimiento y gratitud. Sea como sea, lo que me interesa destacar aquí es que Pothier, consecuente con su esquema, sitúa el arrendamiento de servicios dentro del arrendamiento de cosas, y no dentro del de obra. De la misma forma que un hombre libre rico arrienda una casa que tiene en propiedad, un hombre libre pobre puede arrendarse él mismo, poniéndose al servicio de otro.

Para entender mejor esto, conviene aclarar en qué esta pensando Pothier cuando habla de serviteurs. Afirma, en su Traité des obligations (1761): "El término criados [serviteurs] comprende tanto a aquellos que sirven en torno a la persona del padre de familia como a aquellos que sirven en la agricultura: los servidores de labranza, segadores, obreros que manipulan y transportan haces [calveniers], criados de viticultura, pastores; y también a aquellos que trabajan en las manufacturas: los criados de los refinadores, los trabajadores [ouvriers] que sirven en calidad de oficiales [compagnons] con los artesanos. Bajo este término de criados no están incluidos los jornaleros que trabajan por un jornal [à la journée]"8.

Los serviteurs son todos aquellos que, ya sea en el ámbito estrictamente doméstico, ya sea en la agricultura o en los oficios urbanos, están al servicio del padre de familia, propietario rural o maestro artesano. Todos ellos dependen, en su existencia cotidiana, de un maître, que puede darles órdenes, pero que se compromete, al mismo tiempo, a velar como un padre por su subsistencia. Es muy significativo que Pothier distinga a esta masa de subalternos del tiers état de los jornaleros, que en su época eran especialmente numerosos en el campo.

${ }^{6}$ Véase Alonso Olea, Manuel, Breve nota sobre el arrendamiento de servicios en Pothier, junto con la traducción de algunos pasajes del mismo, en Revista de Politica Social, 117 (1978), pp. 185-195.

${ }^{7}$ Pothier, Robert Joseph, Traité du contrat de louage, cit. (n. 3), pp. 10-11.

${ }^{8}$ Pothier, Robert Joseph, Traité des obligations (París, Debure; Orleans, Rouzeau-Montaut, 1761), II, p. 268. 
Estos últimos, gens de bras, son independientes de un maître, pero porque son independientes - están al margen- de la propia sociedad?

Más adelante, a propósito de la admisión de la prueba testimonial de ciertas personas, Pothier establece una distinción que nos interesa: "Se llama Criados [Serviteurs] a las gentes que tenemos a sueldo [nous avons à nos gages] para que nos presten todos los servicios que les pidamos que nos den, a pesar de que estén encargados principalmente de una especie determinada de servicio. / Así, se puede ser criado sin ser doméstico; tales son un Jardinero o un Guarda de coto que un hombre domiciliado en una ciudad tiene en sus tierras; estos no son propiamente sus domésticos, puesto que no viven con él, y no se sientan a su mesa; pero son sus criados, puesto que los tiene a sueldo, y puede pedirles, cuando va a sus tierras, que le presten todos los servicios para los que estén capacitados. / En esto, estas personas difieren de aquellos con quienes nosotros establecemos un acuerdo [ $m a r-$ ché] para que nos hagan una cierta obra a cambio de una cierta suma de dinero, como por ejemplo los viticultores; estos no son propiamente nuestros criados, y no tenemos derecho a darles órdenes, ni a exigirles otra cosa que la obra que ellos están obligados a hacer" ${ }^{10}$.

Los criados son aquellos que están bajo la autoridad de un amo o maestro, que puede encargarles cualesquiera servicios, más allá de las tareas que tengan habitualmente encomendadas. Tienen por debajo a los jornaleros sans état, y por encima, y esto es lo que nos interesa ahora, a los artesanos. A estos últimos no se les puede dar órdenes sobre su trabajo, y solamente se les puede exigir la obra que se han comprometido a realizar.

Recordemos que Pothier había caracterizado el arrendamiento de servicios, en el que una parte está bajo la autoridad de la otra, dentro del arrendamiento de cosas. La idea es que un hombre libre -es decir, no un siervo de nacimiento, sino una persona que no está vinculada de por vida a un territorio o un amo-, no puede venderse como esclavo, pero sí puede rebajarse a la categoría de criado, alquilando sus servicios por un cierto tiempo. La c o s a que se alquila es la propia persona $\mathrm{o}$, si se quiere, el propio trabajo ${ }^{11}$. Tiene todo el sentido, desde el esquema de Pothier, que esto sea tratado a propósito del arrendamiento de cosas, porque en

${ }^{9}$ En la sociedad francesa de la época existe una marcada división social entre las gens de métier y las gens de bras. El trabajo de las "gentes de oficio", aunque inferior al de las artes nobles -en las que el intelecto pesa más que la mano-, es asimismo claramente distinto del trabajo de las "gentes de brazos". Estos trabajadores no cualificados, llamados a veces hommes de peine, quedan al margen del orden corporativo. Son, igual que los mendigos, las prostitutas, los vagabundos y los pequeños delincuentes, hombres y mujeres sans état. Véase: SEWELL, William H., Jr., Trabajo y revolución en Francia. El lenguaje del movimiento obrero desde el Antiguo Régimen hasta 1848 (trad. cast. de Enrique Gavilán, Madrid, Taurus, 1992), pp. 37-68.

${ }^{10}$ Pothier, Robert Joseph, Traité des obligations, cit. (n. 8), II, pp. 381-382.

${ }^{11}$ Como es sabido, Marx precisará, aunque sea en otro contexto, que lo que se alquila es la fuerza de trabajo. Véase, a este respecto: ENGELs, Friedrich, Introduction to Karl Marx's Wage Labour and Capital (1891 Edition), en MARX, Karl y EngeLs, Friedrich, Collected Works. Volume 27 (1890-1895) (Moscú, Progress Publishers, en colaboración con Londres, Lawrence and Wishart, y Nueva York, International Publishers, 1990), pp. 194-201. 
los contratos de servicios -igual que en el alquiler de una casa, pero a diferencia del teñido de unas telas- el arrendatario es el pagador.

\section{El CARÁCTER PRIVADO DE LA PRESTACIÓN DE SERVICIOS}

La prestación de servicios recibe muy poca atención en el Traité du contrat de louage de Pothier. Se menciona, casi de pasada, a propósito de las c o s a s que pueden ser alquiladas, pero no vendidas. Hemos tenido que acudir al Traité des obligations para entender mejor su significado. Esto, que puede resultar paradójico desde nuestra perspectiva actual, está en consonancia con la sociedad estamental en la que escribe Pothier.

El arrendamiento de servicios no podía recibir una atención excesiva por parte de los juristas anteriores a la Revolución. Puesto que tenía que ver con las relaciones de dependencia entre un amo y un criado, se puede decir que pertenecía a eso que Montesquieu llama derecho doméstico ${ }^{12}$. Propiamente hablando, no era un contrato de arrendamiento - un acuerdo voluntario entre un conducteur y un locateur, cada uno con sus respectivos derechos y obligaciones-, sino una relación temporal de subordinación. En consecuencia, se regulaba de acuerdo con las reglas particulares de cada casa.

Si el arrendamiento de servicios pertenecía al ámbito de la familia, el arrendamiento de cosas y el de obra estaban incluidos en la esfera del derecho natural: "El arrendamiento de obra es, igual que el arrendamiento de cosas, un contrato del derecho de gentes, es decir, no está sujeto de ninguna forma por el Derecho civil, y se rige únicamente por las reglas del Derecho natural"13.

Antes de la Revolución Francesa, el arrendamiento de cosas y el arrendamiento de obra no eran materia del derecho civil, de las normas particulares de la ciudad o comunidad de la que se $\operatorname{tratara}^{14}$, sino que tenían que ver con lo que hoy llamaríamos la "autonomía de la voluntad". Se regían únicamente por los principios del derecho natural, o de la razón universal, mediados por la costumbre.En resumen: mientras el arrendamiento de servicios era una relación de subordinación (regulada por el derecho doméstico), el arrendamiento de obra era un contrato entre hombres libres (regulado por el derecho natural).

De todas formas, estas diferencias entre derecho doméstico (privado) y derecho natural (universal), o entre arrendamiento de servicios y arrendamiento de obra, que he resaltado debido a la importancia que tienen para entender el Código Civil, no están formuladas de forma clara en Pothier. Se pueden rastrear, aislar y explicar,

${ }^{12}$ En Del espiritu de las leyes, al comienzo del libro 26, Montesquieu distingue diversas clases de leyes, afirmando que cada una de ellas debe regular unos asuntos y no otros. Establece la siguiente enumeración, que va de lo más general o universal a lo más particular: derecho natural, derecho divino, derecho canónico, derecho de gentes, derecho político (general y particular), derecho de conquista, derecho civil y derecho doméstico. Véase MonTESQuiEu, De l'esprit des lois (París, Madamme Veuve Dabo, 1824), III, libro 26, capítulo 1, pp. 72-73.

${ }^{13}$ Pothier, Robert Joseph, Traité du contrat de louage, cit. (n. 3), pp. 351-352.

${ }^{14}$ Así es como define Montesquieu el derecho civil, en consonancia con el significado que c i v i 1 tenía en la época. 
pero en ningún caso son distinciones que estructuren el contenido de la obra. La distinción básica que establece Pothier es entre el arrendamiento de cosas -al que dedica, recordemos, la mayor parte del tratado- y el arrendamiento de obra.

\section{LA DUALIDAD DEL ARRENDAMIENTO DE OBRA}

En un punto del libro dedicado al arrendamiento de obra, Pothier explica qué sucede si el arrendatario -es decir, el trabajador- muere con la obra a medio hacer. Frente a quien defiende que el arrendador no debe pagar nada a los herederos del fallecido, el autor sostiene que está obligado a pagar una parte del precio convenido. Argumenta del siguiente modo: "Observad que cuando yo entrego a un trabajador [ouvrier] una obra a hacer, ese contrato contiene dos arrendamientos: el arrendamiento de la obra que se entrega a hacer al trabajador, que es el objeto principal del contrato, y el arrendamiento que el trabajador, arrendatario de la obra que le entrego a hacer [conducteur de l'ouvrage que je lui donne à faire], me hace, por su parte, de su trabajo para la confección de la obra"15.

Aunque Pothier sostenga, fiel a su esquema, que el objeto principal de un contrato de arrendamiento de obra es la obra que se entrega a hacer, reconoce que, al mismo tiempo, el arrendatario-trabajador se convierte en arrendador de su propio trabajo durante el tiempo que dura su faena.

Esta dualidad presente en el arrendamiento de obra había sido reconocida también, de forma aún más clara, por otro célebre jurista francés, Jean Domat. En la primera parte (libro primero, título cuarto) de Les loix civiles dans leur ordre naturel (1689), Domat define el arrendamiento como un contrato por el cual una parte da a la otra el disfrute o el uso de una cosa, o de un trabajo, durante algún tiempo, y a cambio de un cierto precio. Tanto si el arrendamiento es de cosa como si es de trabajo, el que entrega la cosa es el arrendador y el que la recibe el arrendatario, pero con el siguiente matiz: "Aquel que arrienda [baille] una cosa para su disfrute se llama arrendador [le bailleur, ou le locateur], y se da el mismo nombre a aquel que encarga [donne à faire] una obra o un trabajo. Aquel que recibe el disfrute de una cosa por el pago de un alquiler [un louage, ou une ferme], se llama arrendatario [le preneur, ou le conducteur], igual que aquel que emprende un trabajo o una obra, al que se llama también empresario [entrepreneur]. Pero en el arrendamiento de trabajo o industria [les louages, ou prix faits du travail et de l'industrie], los trabajadores o empresarios [ouvriers ou entrepreneurs] hacen también las veces, en cierto sentido, de arrendadores [locateurs], porque alquilan y arriendan [louent et baillent] su esfuerzo [leur peine]"16.

Domat no distingue entre arrendamiento de obra y arrendamiento de servicios. Los trata de forma unitaria en la sección séptima del mencionado título cuarto, a la que denomina "De la nature des prix faits, et autres louages du travail, et de l'industrie" ${ }^{17}$. Tampoco trata como dos categorías separadas el arrendamiento de

${ }^{15}$ Pothier, Robert Joseph, Traité du contrat de louage, cit. (n. 3), pp. 409-410.

${ }^{16}$ Domat, Jean, Les loix civiles dans leur ordre naturel (París, Jean Baptiste Coignard, 1689), pp. 186-187. Volveré sobre este fragmento más adelante, en la sección VI.

${ }^{17}$ Ibíd., pp. 211-213. 
cosas y el de obra. Es por eso que no se encuentra con el problema de indicar si la prestación de servicios pertenece a la primera o a la segunda clase. Se limita a señalar que, en el arrendamiento de trabajo, los arrendatarios-trabajadores son, a su vez, arrendadores de su esfuerzo.

La diferencia que tanto Domat como Pothier observan entre el arrendamiento cosas y el arrendamiento de obra -a saber, el hecho de que, en el segundo, el arrendatario sea, al mismo tiempo, arrendador de su trabajo-, adquirirá una gran importancia en el Código Civil. Dará lugar, como enseguida veremos, a una forma novedosa de entender y de regular el arrendamiento de obra.

\section{El CAmbio introducido por el Código}

Vayamos ya con el examen del Código Civil. El título VIII del libro tercero está dedicado al contrato de arrendamiento (contrat de louage). El primer artículo del título, el 1708, señala que hay dos tipos de contrato de arrendamiento: el de cosas (des choses) y el de obra (d'ouvrage). El arrendamiento de cosas se define en el artículo 1709, en términos muy similares a los de Pothier: "El arrendamiento de cosas es un contrato por el cual una de las partes se compromete [s'oblige] a hacer disfrutar a la otra de una cosa durante un cierto tiempo, a cambio de un determinado precio que esta última se compromete [s'oblige] a pagarle"18.

El arrendamiento de obra se define en el artículo 1710: "El arrendamiento de obra es un contrato por el cual una de las partes se compromete [s'engage] a hacer alguna cosa para la otra, a cambio de un precio acordado entre ellas".

Recordemos que, para Pothier, el arrendamiento de obra es un contrato por el cual una de las partes contratantes da una cierta obra a hacer a la otra. La segunda de las partes se compromete a hacer un trabajo sobre aquello que se le entrega, la primera se compromete a pagar. Obsérvese que, en la definición del Código Civil, desaparece la referencia a la entrega de la obra a hacer por parte de quien encarga el trabajo. Con este pequeño cambio, casi imperceptible, el centro del contrato de obra se desplaza de la obra a realizar, que era el objeto principal del contrato en Pothier, al trabajo mismo. Aunque se siga llamando arrendamiento de obra, estamos hablando de un contrato distinto.

Como ya hemos dicho, en toda locatio conductio hay un locator y un conductor. En el arrendamiento de obra del Código, el locator (arrendador) es el que hace la obra, mientras que el conductor (arrendatario) es el que paga. He aquí la diferencia entre el Código y la tradición jurídica francesa que anunciaba más arriba. Enseguida la explicaré con más detalle.

Troplong señala que el Consejo de Estado había definido el arrendamiento de obra a la manera tradicional, como un contrato por el cual una de las partes da a la otra cierta cosa a hacer, de forma que quien paga es el arrendador, y el trabajador es el arrendatario. El Tribunato, sin embargo, propuso modificar el texto, de forma que se escribiera "se compromete a hacer alguna cosa para la otra",

\footnotetext{
${ }^{18}$ La edición original del Code civil des Français (1804) está disponible en Gallica: https://gallica.bnf.fr/ark:/12148/bpt6k1061517
} 
en lugar de "da alguna cosa a hacer"19. De esta manera, se invierten los papeles: el trabajador deviene arrendador y el que paga arrendatario. El tribuno Moricault lo expresa con total claridad: "Las atenciones [soins], los servicios, el trabajo y la industria son la materia del contrato de arrendamiento de obra: eso es lo que se da en alquiler, eso es lo que se paga. Por lo tanto, el guarda [gardien], el criado [serviteur], el artesano, el trabajador [ouvrier] o el empresario [entrepreneur] es el verdadero arrendador [locateur]; quien les paga es el verdadero arrendatario [locataire ou conducteur]; y es inapropiado que, en las leyes y en las obras de los jurisconsultos, estas cualidades hayan sido invertidas"20.

Prosigamos con el análisis de los artículos. En el 1711 se afirma que los dos tipos de arrendamiento (cosas y obra) se dividen, a su vez, en cinco subtipos particulares. Aunque no se diga expresamente, tres de los subtipos que se enumeran son arrendamientos de cosas, mientras que los dos restantes son arrendamientos de obra. El primero, segundo y cuarto son el bail à loyer, bail à ferme y bail à cheptel, es decir, el alquiler de casas o bienes muebles, el de fincas rurales y el de animales, respectivamente ${ }^{21}$. El tercero y el quinto son el loyer, por un lado, y el devis, marché o prix fait, por el otro. El loyer, que puede traducirse genéricamente como alquiler, tiene aquí un sentido más específico: es el arrendamiento de trabajo, industria o servicios. Por otra parte, el Código utiliza como sinónimos devis, marché y prix fait, que pueden traducirse como presupuesto, acuerdo y precio fijo. Su objetivo es la realización de una obra (l'enterprise d'un ouvrage) a cambio de un precio fijado de antemano, y siempre que la materia la proporcione aquel para el que se hace la obra.

Por lo tanto, el louage d'ouvrage abarca, en el Código, no solo el contrato de obra propiamente dicho (prix fait), sino también el arrendamiento de trabajo, industria o servicios (loyer), que Pothier entendía como arrendamiento de cosas y no de obra ${ }^{22}$. Lejos de ser una mera ampliación extensional, estamos ante un cambio intensional. Dicho de forma más clara: no se trata solamente de que el arrendamiento de obra aumente su extensión hasta englobar al contrato de servicios, sino de que esta inclusión modifica la propia manera de entender el contrato de obra en sentido estricto, al invertir las figuras de arrendatario y arrendador.

En Pothier, un propietario puede poseer una casa y alquilarla a terceros, y también tener criados domésticos en alquiler. Por otro lado, puede poseer un terreno y, a fin de construir una casa en él, a lquilárs el o por un tiempo a un arquitecto para que realice la obra; o poseer unas telas y a l qu i lá r s e l a s a un sastre para la confección de un vestido. En los dos primeros casos (arrendamiento de cosas), el arrendador cobra: ya sea el propietario de la casa, ya sean los

\footnotetext{
${ }^{19}$ Troplong, Raymond-Theodore, De l'échange et du louage. Commentaire des titres VII et VIII du libre III du Code civil (Bruselas, Meline, Cans et Compagnie, 1841), p. 55.

${ }^{20}$ Fenet, Pierre-Antoine, Recueil complet des travaux préparatoires du Code civil (París, Videcoq, 1836), XIV, pp. 338-339.

${ }^{21}$ Las diferencias entre estos tres subtipos no me interesan aquí. En lo que sigue, hablaré del arrendamiento de cosas en general.

${ }^{22}$ Para no confundirlo con el prix fait, en adelante me referiré al louage d'ouvrage del artículo 1710 como "arrendamiento de obra y servicios" o "arrendamiento de obra e industria".
} 
criados que alquilan sus servicios. En las otras dos circunstancias (arrendamiento de obra), el arrendador paga.

En el Código, las cosas se ven de otra manera. Por un lado, un propietario puede tener una casa y alquilarla. Por otra parte, una persona puede alquilar sus propios servicios a terceros, ya sea para la realización de una obra (la construcción de una casa, la confección de un vestido), ya sea para tareas de servicio doméstico. El arrendador, en los tres casos (arrendamiento de cosas, arrendamiento de obra, arrendamiento de servicios), es la parte del contrato que cobra ${ }^{23}$.

Ahora, el foco ya no se pone en quien entrega y quien recibe, sino en quien paga y quien cobra. Solo así es posible considerar el loyer (lo que luego se dará en llamar locatio conductio operarum) y el prix fait (la locatio conductio operis) como dos subtipos del arrendamiento de obra y servicios. En ambos casos, de acuerdo con la lógica del Código, aquello que se alquila es el trabajo. En consecuencia, el arrendatario es siempre la parte que encarga la obra, tenga o no poder de mando sobre su desarrollo, porque en ambos casos es quien paga. El que paga por el trabajo de un artesano y el que paga por los servicios de un criado son ambos arrendatarios, porque se comprometen a entregar una suma de dinero por aquello que se arrienda.

Aunque pueda parecer una obviedad, vale la pena recordar que, para poder arrendar una cosa, antes hay que ser propietario de esa cosa. Esta es la razón de que, en el arrendamiento de cosas según Pothier, la figura del pagador esté asociada con el arrendatario, y la del cobrador con el arrendador, y viceversa en el arrendamiento de obra. Uno es p r o p i e t a r i o de una casa, la alquila, y c o b r a por ello. Uno es p r o p i e t a r i o de unas telas, las alquila a un sastre para realizar una obra con ellas, y p a g a por ello. Lo que importa para determinar la figura del arrendador no es quién paga y quien cobra, sino quién es propietario de la cosa.

En cambio, en el Código, el arrendador es siempre la parte que cobra. Siendo así, cabe preguntarse, ¿cuál es la propiedad que se alquila en el arrendamiento de obra y servicios? Esa propiedad es el propio trabajo del individuo. Sería exagerado decir que es el Código el que introduce esta idea. Como ya hemos visto a propósito de unos fragmentos de Pothier y Domat, su origen se puede rastrear mucho más atrás. Lo que hace el Código es otorgarle una importancia mucho mayor a esta circunstancia, hasta el punto de que provoca la inversión en las figuras del arrendador y del arrendatario en el arrendamiento de obra y servicios. Ahora, el centro del contrato ya no está en lo que se entrega, sino en quién es p r o p i e t a r i o del trabajo. Lo que permite la inversión de la que venimos hablando, por lo tanto, es el presupuesto de que la fuerza de trabajo es una propiedad como otra cualquiera.

\footnotetext{
${ }^{23}$ En puridad, la nueva terminología presenta algunos problemas, en la medida en que desaparece el vínculo entre locare y c o l o c a r, y entre conducere y ll e v a r c o n s i g o : hay locateurs que reciben en lugar de entregar (un artesano que recibe un encargo) y conducteurs que se limitan a pagar, sin dirigir o c o n d u c i r la obra a realizar (un propietario que hace construir una casa en su terreno). Atendiendo a la etimología, no tiene mucho sentido decir que quien entrega una tela a un sastre para la confección de un vestido, sin poder darle órdenes, es el conducteur: parece evidente que, tal como hacía la tradición, hay que considerarlo un arrendador, un locateur.
} 
Se puede decir que esta regulación que hace el Código Civil del arrendamiento de obra e industria supone un gran paso adelante, pero también un retroceso. Vayamos primero con la cara, antes de hablar de la cruz. Si bien sigue habiendo criados, sus servicios ya no se consideran como un tipo particular dentro del arrendamiento de cosas. Después de la Revolución Francesa, este tipo de actividades ya no pueden regirse por unas normas al margen de la comunidad política. Los domésticos no tienen los mismos derechos y obligaciones que los demás trabajadores, pero son personas igual que todas las demás.

Sin embargo, por otra parte, esta igualdad en la categoría de persona se encuentra disociada de las condiciones materiales de vida de las partes contratantes. Cuando alguien cobra por el alquiler de una casa, es porque es propietario de esa casa puesta en alquiler. El a r r e n d a d o r es la parte fuerte de la relación contractual: es el propietario. Cuando alguien cobra por haber alquilado su fuerza de trabajo, es porque está desposeído de los medios para producir por sí mismo. El a r r e n d a d o r es la parte débil de la relación contractual: es el proletario. En la lógica antigua, esto no sucedía: si exceptuamos los servicios de los criados-que jugaban en otra liga-, el arrendador era siempre el propietario.

En definitiva: la regulación del arrendamiento de obra y servicios en el Código no tiene en cuenta las desigualdades de poder económico ni las relaciones de propiedad existentes en la sociedad civil. La capacidad de pagar estructura la nueva forma de entender este contrato, dejando a un lado el hecho de que solo unos pocos la poseen de forma efectiva, mientras la mayoría se ve obligada a cobrar, es decir, a alquilar su fuerza de trabajo.

\section{GENS DE TRAVAIL Y ENTREPRENEURS D'OUVRAGES}

Después de ocuparse del arrendamiento de cosas, el Código Civil dedica el tercer capítulo del título VIII al arrendamiento de obra y servicios, aunque ahora le llama "arrendamiento de obra e industria"24. El artículo 1779 dice así: "Hay tres clases principales de arrendamiento de obra y de industria: 1. El arrendamiento de gentes de trabajo [gens de travail] que se ponen al servicio de alguien. 2. El de conductores, tanto por tierra como por agua, que se encargan del transporte de personas o de mercancías. 3. El de quienes emprenden obras [entrepreneurs d'ouvrages], como resultado de un presupuesto o un acuerdo [devis ou marchés]".

Nos interesan el primer y el tercer tipo de contratos, es decir, el arrendamiento

${ }^{24}$ Sobre el arrendamiento de obra e industria en el Código Civil francés, véase Dufour, Julien-Michel, Code civil des Français, avec les sources où toutes ses dispositions ont été puisées (París, Imprimerie de Jeunehomme, 1806), III, pp. 235-246; GRENIER de CARDENAL, Joseph, $D u$ louage d'ouvrage et d'industrie en droit romain et en droit français (tesis doctoral, Faculté de Droit de Toulouse, 1874); Guillouard, Louis-Vincent, Traité du contrat de louage (París, A. Durand et Pedone-Lauriel, 1887), II, pp. 206-411; Solé Resina, Judith, Delimitación del objeto del contrato de arrendamiento de obras o servicios (tesis doctoral, Universitat Autònoma de Barcelona, 1996), pp. 2-49; SEVERIN Fuster, Gonzalo, La recepción del modelo de la locatio conductio' en la regulación del 'arrendamiento de obras y servicios' del Código civil español de 1889, en REHJ., 38 (2016), pp. 209-221. 
de servicios y el de obra: el loyer, por un lado, y el prix fait, por el otro. Son tratados en los artículos 1780-1781 y 1787-1799, respectivamente.

Vayamos primero con el loyer. El título de la sección que encabeza los artículos 1780 y 1781 habla de arrendamiento de "domésticos y trabajadores" (domestiques et ouvriers), quienes, recordemos, son llamados "gentes de trabajo" en el artículo 1779. El hecho de que el Código sitúe a los ouvriers junto a los domestiques, que son todos aquellos que están al servicio de un amo o maestro, requiere una explicación.

En el fragmento de Domat recogido más arriba (de finales del siglo XVII), ouvrier se usa como sinónimo de entrepreneur: es el maestro artesano, aquel que es experto en un determinado tipo de ouvrage. En cualquier caso, al menos desde la segunda mitad del siglo XVIII, ouvrier designa, de forma preferente, a los compagnons que están bajo la autoridad del maître o entrepreneur. Estos ouvriers o compagnons, aunque dependan del maestro en sus respectivos oficios, adquieren un grado considerable de autonomía ya antes de la Revolución Francesa. Si bien algunos son tratados como criados [serviteurs], sometidos a obligaciones de subordinación, en determinados lugares y oficios son considerados como conducteurs d'ouvrage, en posición de reciprocidad con sus empleadores ${ }^{25}$. Muchos tienen casa y familia propias. A partir de la promulgación del decreto de Allarde (marzo de 1791), estos compagnons ya no forman parte, al menos oficialmente, de los antiguos oficios jurados, por lo que se quedan en una suerte de tierra de nadie. De 1792 en adelante se mezclan con algunos de sus antiguos maestros, y juntos forman el movimiento sans-culotte, que llega a tener una influencia decisiva en el gobierno de la nación ${ }^{26}$.

En las primeras décadas del siglo XIX, surge -en Francia todavía de forma muy incipiente- una nueva clase social: el proletariado industrial. Estos proletarios son los herederos de esas gens de bras de las que hemos hablado al inicio. Journaliers de la industria moderna, están sometidos al poder despótico de los jefes de industria. Aunque entre ambos no exista el mismo tipo de relación paternal que se daba entre los amos y sus criados, se puede decir, aunque sea figuradamente, que los proletarios son los domésticos del nuevo siglo. Están separados socialmente de los ouvriers de los oficios urbanos. A pesar de todas las transformaciones de esos años, estos últimos conservan muchas de las prácticas gremiales. Generalmente cobran por su trabajo a prix fait, y no están sometidos a una disciplina equiparable a la de la gran industria.

El Código Civil, decíamos, sitúa a los ouvriers al lado de los domésticos, en los artículos dedicados al loyer. Esto podría llevar a pensar que desaparece, a la baja, la mencionada distinción entre trabajadores cualificados urbanos, que cobran a prix fait, y aquellos que reciben un jornal. Sin embargo, la interpretación mayoritaria durante el siglo XIX consiste en afirmar que los artículos 1780 y 1781

${ }^{25}$ Véase KaPLAN, Steven Laurence, Réflexions sur la police du monde du travail, 1700-1815, en Revue Historique, 103/261 (1979), pp. 17-77; Sonenscher, Michael, Work and Wages. Natural Law, Politics \& the Eighteen-Century French trades (Cambridge, Cambridge University Press, 2011).

${ }^{26}$ Véase SoBoul, Albert, Los sans-culottes. Movimiento populary gobierno revolucionario (trad. cast. de María Ruipérez y Jesús Bravo, Madrid, Alianza, 1987). 
del Código no están pensados para todo tipo de ouvriers, sino solamente para los trabajadores de determinados oficios. El comentarista Victor-Napoléon Marcadé señala, en este sentido, que el término ouvriers no se refiere aquí a todos los que así se califican en el lenguaje habitual, sino solamente a quienes se someten a una mayor dependencia y se arriendan por un determinado período. Los demás, aunque realicen trabajos manuales, al trabajar por pieza, a cambio de un precio fijo por cada obra, no entran en la primera sección de las establecidas por el artículo 1779 , sino en la tercera ${ }^{27}$.

En definitiva: el título de los artículos 1780 y 1781 llama ouvriers a quienes, aun sin ser estrictamente domésticos, arriendan sus servicios a un maestro. Son aquellos a los que Pothier, si se recuerda, llamaba serviteurs. En el lenguaje de la época, sin embargo, se llama ouvriers, de forma preferente, a los trabajadores de los oficios urbanos, cuyas actividades son reguladas por otro grupo de artículos. Los antiguos compagnons quedan así situados a medio camino entre la primera y la tercera sección del capítulo, una ambigüedad resoluble únicamente a través de la interpretación.

El artículo 1780 afirma: "Los servicios solamente se pueden contratar por un cierto periodo de tiempo, o para una empresa determinada".

Esto es un gran paso adelante: sigue habiendo criados, pero ya no hay sirvientes de por vida. Tras la Revolución Francesa, no es posible seguir conservando este tipo de servidumbre entre los hombres libres ${ }^{28}$.

A cambio, el artículo 1781 consagra la inferioridad legal de los domestiques y ouvriers frente al empleador, en la medida en que la palabra de este último prevalece ante los tribunales en caso de conflicto: "El maestro es creído en sus afirmaciones sobre la cuota de los salarios [quotité des gages], el pago del salario del año anterior [salaire de l'année échue] y las cuentas del año en curso [à-comptes donnés pour l'année courante]"29.

Tras ocuparse de los transportistas, el Código Civil trata el tercer tipo de arrendamiento de obra y servicios: los devis, marchés o prix faits. La tradición romanista consideraba que, en este tipo de arrendamiento, los materiales debe suministrarlos la persona para la que se hace la obra. Si el encargado de poner el trabajo ponía además los materiales, se consideraba un contrato de compraventa, y no de arrendamiento. En el artículo 1711, recordemos, el Código civil está en consonancia con esta tradición. Sin embargo, el artículo 1787 afirma: "Cuando se

${ }^{27}$ MARCADÉ, Victor-Napoléon, Explication théorique et practique du Code civil : contenant l'analyse critique des auteurs et de la jurisprudence et un traité résumé après le commentaire de chaque titre (París, Delamotte et Fils, 1875) VI, p. 546.

${ }^{28} \mathrm{Al}$ menos no en la metrópolis; cosa distinta son las colonias. Véase LosUrdo, Domenico, Contrahistoria del liberalismo (trad. cast. de Marcia Gasca y Joaquín Miras, Barcelona, El Viejo Topo, 2007).

${ }^{29}$ Para la historia de este artículo, que fue abrogado el 2 de agosto de 1868, véase CASTALDO, André, L'histoire juridique de l'article 1781 du Code civil : 'Le maître est cru sur son affirmation', en Revue Historique de Droit Français et Étranger, 55/2 (1977), pp. 211-237. El Código Civil español (1889) sigue hablando, aún hoy, de amos y de criados. En el artículo 1584 puede leerse: "El amo será creido, salvo prueba en contrario: 1) Sobre el tanto del salario del sirviente doméstico.

2) Sobre el pago de los salarios devengados en el año corriente". 
encarga a alguien hacer una obra, se puede acordar que este proporcionará solamente su trabajo o su industria, o que también proporcionará el material'.

Esta contradicción entre los artículos 1711 y 1787 del Código dio lugar a una discusión doctrinal entre los civilistas franceses, en la que no entraré. Únicamente me interesa destacar que es el cambio en el objeto de este tipo de contratos-que ya hemos señalado más arriba- lo que hace posible que pueda haber arrendamientos de obra sin transmisión de materiales. Cuando el centro del arrendamiento de obra era la cosa entregada, si no había entrega, porque el trabajador ponía los materiales, entonces no había arrendamiento, sino compra. Sin embargo, ahora que el centro del arrendamiento de obra es el trabajo mismo, y que los roles de arrendador y arrendatario han cambiado, es posible un arrendamiento sin entrega: lo que cuenta es que quien encarga pague al trabajador por su trabajo.

El resultado de esto es que se difumina la frontera entre el contrato de obra y el de servicios. En realidad, siendo más precisos, en la medida en que la distinción entre locatio conductio operis y locatio conductio operarum no es anterior, sino posterior al Código, lo que sucede es que se modifica la naturaleza del arrendamiento de obra, que se empieza a pensar como arrendamiento de obra y servicios, con dos variantes en su seno, pero que responden ambas al mismo esquema: en ambos casos, el trabajador arrienda su trabajo, en ambos casos es el arrendador. Antes, en cambio, el arrendamiento de obra y el arrendamiento de servicios diferían en los papeles asignados al trabajador: el artesano encargado de una obra era fundamentalmente arrendatario, mientras que el criado que se ponía a disposición de un maestro era arrendador de su propio trabajo.

Esto no quiere decir que la equiparación sea total. En la práctica, se conservan las diferencias de tratamiento, y el propio Código se hace eco de ellas, al situar al artesano y al criado en dos secciones separadas. En los devis o marchés (artículos 1787-1799), el precio del trabajo corresponde a una obra o tarea determinadas de antemano. En cambio, en el arrendamiento de gens de travail (artículos 17801781), el precio se paga en razón del tiempo que los trabajadores están a disposición de quien los emplea, sea cual sea el resultado de su trabajo. Además, a diferencia de los primeros, que son independientes en las tareas a realizar, los segundos están sometidos a las órdenes del maestro. Los primeros, en fin, tienen derechos y obligaciones, mientras que los segundos no son creídos ante los tribunales si su testimonio entra en contradicción con el de su arrendatario.

No es casualidad que el Código, todavía pegado a la tradición, se centre, en esta sección dedicada a los prix faits, en la construcción de casas, que desde antiguo se consideraban arrendamiento de obra, al poner el arrendador el terreno. A lo largo de varios artículos, se señalan las diferentes obligaciones de quien encarga la obra (maître) y de quien la realiza (llamado indistintamente architecte, ouvrier o entrepreneur). El último artículo de la sección (1799) dice así: "Los albañiles, carpinteros, cerrajeros y otros trabajadores [ouvriers] que hacen directamente acuerdos a un precio fijo [marchés à prix fait] están sujetos a las reglas prescritas en esta sección: son empresarios [entrepreneurs] en la parte en que ellos tratan".

Cuando quien se encarga de hacer la casa para el maître no es un arquitecto, que tiene a su cargo a un determinado número de trabajadores, sino que son los 
trabajadores mismos, entonces estos deben ser considerados como entrepreneurs d'ouvrages, y no como simples serviteurs. Aunque pensada para la construcción de casas, esta disposición es susceptible de aplicarse a casos análogos.

Este último artículo (1799) es una buena prueba de que el Código, a pesar de cambiar la naturaleza del arrendamiento de obra, sigue separando a los trabajadores de los oficios -o al menos a algunos de ellos- de los domésticos. Como se habrá notado, el texto habla de ouvriers, pero ahora aparecen asimilados -igual que en Domat- a los entrepreneurs. Son maestros u oficiales artesanos, a quienes se paga por la obra realizada. En cambio, los ouvriers de los que hemos hablado antes -aquellos que, junto a los domésticos, dan título a la sección que encabeza los artículos 1780 y 1781 - son otro tipo de trabajadores, menos cualificados; se les paga por día, semana, mes, o el tiempo que sea, a fin de tenerlos a disposición y poder darles órdenes mientras dure el contrato.

\section{CONCLUSIÓN}

El Código Civil introduce una modificación importante en el arrendamiento de obra e industria con respecto a la tradición jurídica francesa: el centro del contrato deja de ser aquello que se entrega y pasa a tener que ver con quién paga y quién cobra. Esta forma de ver las cosas - a la que subyace la idea de que la fuerza de trabajo humana es una propiedad como otra cualquiera-, tiene la ventaja de que deja de considerar los servicios de los criados como arrendamiento de cosas, y la desventaja de que no tiene en cuenta quién es la parte débil de la relación contractual. Supone, además, una cierta equiparación, a la baja, entre arrendamiento de obra y arrendamiento de servicios. El artesano pasa a ser un arrendador, igual que el criado. Esto no significa, de todas formas, que ambos sean tratados de la misma manera: el Código dedica grupos distintos de artículos a unos y a otros. Las gens de travail están a disposición de quien los emplea, mientras que los entrepreneurs d'ouvrages gozan de independencia en las tareas a realizar.

Este análisis, más allá del valor que pueda tener por sí mismo, y del provecho que quizás puedan sacar de él los especialistas, me parece que arroja luz sobre -al menos- dos cuestiones de un alcance mayor. La primera está más directamente relacionada con lo dicho hasta ahora, mientras que la segunda excede, en realidad, a las pretensiones de este artículo. Me limito, en ambos casos, a señalarlas de forma breve.

La primera es que el significado histórico del Código napoleónico no debe interpretarse de forma retrospectiva, sino atendiendo al contexto en el que este se inserta. A principios del XIX, y durante toda la primera mitad de dicho siglo, se mantiene en Francia la distinción tradicional entre gens de bras y gens de métier ${ }^{30}$. Se conserva en la práctica, y el Código - a pesar de introducir novedades importantes en la forma de entender el arrendamiento de obra e industria- se hace eco de ella. Lo que ahora me interesa destacar es que esta advertencia no solamente es válida para este caso concreto: las novedades introducidas por el Código, que no

${ }^{30}$ Sewell, William H., Jr., Trabajo y revolución en Francia, cit. (n. 7), p. 266. 
son pocas, solo se alcanzan a comprender plenamente si no se pierden de vista la sociedad y la tradición jurídica de las que surge este célebre texto.

Esto nos lleva a la segunda cuestión: el arrendamiento de obra e industria del Código napoleónico no es, al menos no de forma directa, el antecedente del contrato de trabajo surgido en Europa a finales del siglo XIX. El Código dedica más bien pocos artículos a las relaciones entre trabajadores y maestros, dejando un vacío que es colmado por un derecho laboral casuístico. Elaborado en buena medida a partir de las decisiones de los conseils de prud'hommes-muy influidas por las prácticas y costumbres locales-, funciona relativamente al margen del legicentrismo dominante ${ }^{31}$. A pesar de no ser igualitario, tiene un carácter garantista con los compagnons de los oficios urbanos. Sin embargo, a medida que se introducen las nuevas fábricas, los jornaleros que trabajan en ellas se ven sometidos a un tipo de dependencia similar a la de los domésticos. Las condiciones de trabajo y de vida de estos proletarios, todavía minoritarios en Francia a mediados de siglo, se distinguen cada vez más de las de los trabajadores de los oficios urbanos. El resultado es que la jurisprudencia laboral garantista va perdiendo peso en favor de los reglamentos de taller, cuyo carácter disciplinario refuerza la subordinación de los trabajadores con respecto a la persona del patrón ${ }^{32}$. La doctrina no se hace eco de este cambio de forma inmediata. No es hasta 1886, cuando Ernest D. Glasson publica Le Code civil et la question ouvrière, que se empieza a popularizar la expresión "contrato de trabajo". Según Cottereau, es aquí donde hay que ir a buscar el origen de la definitiva equiparación, a la baja, entre el arrendamiento de obra y el arrendamiento de servicios ${ }^{33}$. El contrato de trabajo debe entenderse, pues, como una evolución de los reglamentos de taller de las grandes fábricas, no del contrato de arrendamiento de obra e industria del Código Civil ${ }^{34}$.

Será para hacer frente a los problemas derivados de la subordinación de los trabajadores a los empresarios que surgirá, a principios del siglo XX, el derecho del trabajo. Me parece que hoy, ante las amenazas crecientes a las que se enfrenta este último, el estudio de las regulaciones anteriores al surgimiento del contrato de trabajo cobra una gran actualidad. No para subirse al carro de quienes celebran la nueva flexibilidad, sino justamente para buscar formas novedosas de reforzar a la parte débil de la relación contractual.

\footnotetext{
${ }^{31}$ COTTEREAU, Alain, Sens du juste et usages du droit du travail : une évolution contrastée entre la France et la Grande-Bretagne au XIXe Siècle, en Revue d'Histoire du XIXe Siècle, 33 (2006), p. 102.

${ }^{32}$ COTTEREAU, Alain, Justice et injustice ordinaire sur les lieux de travail d'après les audiences prud'homales (1806-1866), en Le Mouvement Social, 141 (1987), pp. 55-58.

${ }^{33}$ Cottereau, Alain, Droit et bon droit. Un droit des ouvriers instauré, puis évincé par le droit du travail (France, XIXe siècle), en Annales. Histoire, Sciences Sociales, 57/6 (2002), p. 1544.

${ }^{34}$ OJeda Avilés, Antonio, La genealogía del contrato de trabajo, en Civitas. Revista Española de Derecho del Trabajo, 135 (2007), pp. 543-547.
} 


\section{BiBLIOGRAFÍA}

Alonso Olea, Manuel, Breve nota sobre el arrendamiento de servicios en Pothier, junto con la traducción de algunos pasajes del mismo, en Revista de Política Social, 117 (1978), pp. 185-195.

CASTALDO, André, L'histoire juridique de l'article 1781 du Code civil : 'Le maître est cru sur son affirmation', en Revue Historique de Droit Français et Étranger, 55/2 (1977), pp. 211-237.

Cottereau, Alain, Droit et bon droit. Un droit des ouvriers instauré, puis évincé par le droit du travail (France, XIXe siècle), en Annales. Histoire, Sciences Sociales, 57/6 (2002), pp. 1521-1557.

-Justice et injustice ordinaire sur les lieux de travail d'après les audiences prud'homales (1806-1866), en Le Mouvement Social, 141 (1987), pp. 25-59.

- Sens du juste et usages du droit du travail : une évolution contrastée entre la France et la Grande-Bretagne au XIXe Siècle, en Revue d'Histoire du XIXe Siècle, 33 (2006), pp. 101-120.

Dомат, Jean, Les loix civiles dans leur ordre naturel (París, Jean Baptiste Coignard, 1689).

Dufour, Julien-Michel, Code civil des Français, avec les sources où toutes ses dispositions ont été puisées (París, Imprimerie de Jeunehomme, 1806).

EnGELS, Friedrich, Introduction to Karl Marx's Wage Labour and Capital (1891 Edition), en Marx, Karl y Engels, Friedrich, Collected Works. Volume 27 (1890-1895) (Moscú, Progress Publishers, en colaboración con Londres, Lawrence and Wishart, y Nueva York, International Publishers, 1990).

FENET, Pierre-Antoine, Recueil complet des travaux préparatoires du Code civil (París, Videcoq, 1836).

Grenier de Cardenal, Joseph, Du louage d'ouvrage et d'industrie en droit romain et en droit français (tesis doctoral, Faculté de Droit de Toulouse, 1874).

Guillouard, Louis-Vincent, Traité du contrat de louage (París, A. Durand et PedoneLauriel, 1887).

Kaplan, Steven Laurence, Réflexions sur la police du monde du travail, 1700-1815, en Revue Historique, 103/261 (1979), pp. 17-77.

Losurdo, Domenico, Contrahistoria del liberalismo (trad. cast. de Marcia Gasca y Joaquín Miras, Barcelona, El Viejo Topo, 2007).

MarCADÉ, Victor-Napoléon, Explication théorique et practique du Code civil : contenant l'analyse critique des auteurs et de la jurisprudence et un traité résumé après le commentaire de chaque titre (París, Delamotte et Fils, 1875).

Montesquieu, De l'esprit des lois (París, Madame Veuve Dabo, 1824).

OJeDa Avilés, Antonio, La genealogía del contrato de trabajo, en Civitas. Revista Española de Derecho del Trabajo, 135 (2007), pp. 533-555.

Pothier, Robert Joseph, Traité des obligations (París, Debure; Orleans, RouzeauMontaut, 1761).

-Traité du contrat de louage, selon les règles tant du for de la conscience, que du for extérieur (París, Debure; Orleans, Rouzeau-Montaut, 1764).

Sala Bañuls, Juan; lópez Clarós, Pedro y Fábregas del Pilar, Francisco, Digesto romano-español (2a ed., Madrid, Imprenta de la Viuda de Domínguez, 1856).

Schulz, Fritz, Derecho romano clásico (trad. cast. de José Santa Cruz Teigeiro, Barcelona, Bosch, 1960). 
SEVERIN Fuster, Gonzalo, La recepción del modelo de la locatio conductio' en la regulación del 'arrendamiento de obras y servicios' del Código civil español de 1889, en REHJ., 38 (2016), pp. 201-231.

Sewell, William H., Jr., Trabajo y revolución en Francia. El lenguaje del movimiento obrero desde el Antiguo Régimen hasta 1848 (trad. cast. de Enrique Gavilán, Madrid, Taurus, 1992).

Soboul, Albert, Los sans-culottes. Movimiento popular y gobierno revolucionario (trad. cast. de María Ruipérez y Jesús Bravo, Madrid, Alianza, 1987).

Solé Resina, Judith, Delimitación del objeto del contrato de arrendamiento de obras o servicios (tesis doctoral, Universidad Autónoma de Barcelona, 1996).

Sonenscher, Michael, Work and Wages. Natural Law, Politics \& the Eighteen-Century French trades (Cambridge, Cambridge University Press, 2011).

Troplong, Raymond-Theodore, De l'échange et du louage. Commentaire des titres VII et VIII du libre III du Code civil (Bruselas, Meline, Cans et Compagnie, 1841). 